\title{
(6) OPEN ACCESS \\ Large-scale data reporting of paediatric morbidity and mortality in developing countries: it can be done
}

Trevor Duke, ${ }_{1}^{1,2}$ Edilson Yano, ${ }^{3}$ Adrian Hutchinson ${ }^{4}$ Illomo Hwaihwanje, ${ }^{5}$ Jimmy Aipit, ${ }^{6}$ Mathias Tovilu, ${ }^{7}$ Tarcisius Uluk, ${ }^{8}$ Theresia Rongap, ${ }_{1}^{9}$ Beryl Vetuna, ${ }^{10}$ William Lagani, ${ }^{11}$ James Amini, ${ }^{12}$ on behalf of the Paediatric Society of Papua New Guinea

- Additional material is published online only. To view please visit the journal online (http://dx.doi.org/10.1136/ archdischild-2015-309353).

For numbered affiliations see end of article.

\section{Correspondence to} Professor Trevor Duke, Centre for International Child Health, University of Melbourne, MCRI, Royal Children's Hospital, Flemington Road, Parkville, VIC 3052, Australia; trevor.duke@rch.org.au

Received 17 July 2015 Revised 7 September 2015 Accepted 10 September 2015 Published Online First 21 October 2015

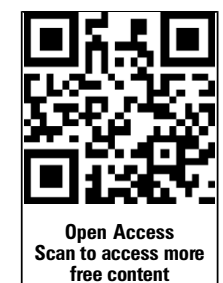

CrossMark

To cite: Duke $\mathrm{T}$, Yano $\mathrm{E}$ Hutchinson A, et al. Arch Dis Child 2016;101: 392-397.

\section{ABSTRACT}

Although the WHO recommends all countries use International Classification of Diseases (ICD)-10 coding for reporting health data, accurate health facility data are rarely available in developing or low and middle income countries. Compliance with ICD-10 is extremely resource intensive, and the lack of real data seriously undermines evidence-based approaches to improving quality of care and to clinical and public health programme management. We developed a simple tool for the collection of accurate admission and outcome data and implemented it in 16 provincial hospitals in Papua New Guinea over 6 years. The programme was low cost and easy to use by ward clerks and nurses. Over 6 years, it gathered data on the causes of 96998 admissions of children and 7128 deaths. National reports on child morbidity and mortality were produced each year summarising the incidence and mortality rates for 21 common conditions of children and newborns, and the lessons learned for policy and practice. These data informed the National Policy and Plan for Child Health, triggered the implementation of a process of clinical quality improvement and other interventions to reduce mortality in the neediest areas, focusing on diseases with the highest burdens. It is possible to collect large-scale data on paediatric morbidity and mortality, to be used locally by health workers who gather it, and nationally for improving policy and practice, even in very resource-limited settings where ICD-10 coding systems such as those that exist in some high-income countries are not feasible or affordable.

\section{INTRODUCTION}

Since 1967, the WHO has recommended that all member states use the International Classification of Diseases (ICD) coding. However, by 2005 only 23 countries were considered to have high-quality death registration data (quality criteria based on timeliness, completeness, coverage and the sparing use of codes for ill-defined causes). ${ }^{1}$ These were wealthy countries using ICD-10 coding for cost reimbursement health financing systems based on diagnoses.

Developing or low and middle income countries have not kept pace with diagnostic precision required for optimal classification using ICD-10, and the resource requirements for ICD-10 conformity are considerable. ${ }^{2}$ It is particularly beyond the capacities of poorly resourced provincial and district hospitals in low/middle-income countries. The consequences are that almost no standardised data are available from non-tertiary health facilities in low/ middle-income countries, and the data that exist comes from tertiary facilities that have diagnosticbased funding models or insurance schemes. At the same time as recommending this complex coding system, at the clinical level WHO recommends simpler syndromic diagnoses for common childhood conditions, based on the Integrated Management of Childhood Illness (IMCI), Hospital Care for Children and other disease-specific guidelines. ${ }^{3} 4$

We sought to develop a tool for recording and monitoring admissions of children to hospitals that could be implemented on a large scale in settings with very limited resources. The programme requires only basic patient demographic information and diagnoses that are routinely recorded in admission/discharge record books kept in most children's wards. The diagnoses had to be consistent with those used by the WHO in clinical guidelines, and consistent with those in ICD-10 coding systems, but less numerous, not reliant on laboratory tests that were not available, and the diagnoses had to be easy to identify and record by ward clerks or nurses with minimal training.

In 2007-2008 we designed the Paediatric Hospital Reporting (PHR) programme and progressively implemented it on a national scale. We report the development, implementation, and outcomes of the PHR over 6 years in Papua New Guinea (PNG).

\section{METHOD}

Design characteristics and processes

The programme was developed in PNG and Australia. In 2008 a meeting of all PNG paediatricians, Ministry of Health officials and academics proposed the diagnoses to be included in the initial version. These included all conditions in the WHO IMCI and Hospital Care for Children guidelines, and the PNG Standard Treatment Manual for Common Illnesses. ${ }^{3}$ The diagnoses were standardised, consistent with WHO definitions and ICD-10, although numerical coding was not used. The programme was made using FileMaker Pro (http://www.filemaker.com/) at a development cost of less than US\$10 000 spread over 6 years.

Because the manual calculation of basic statistics in health reports is often incorrect, the programme needed to automatically calculate the number of admissions for common diagnoses, the number of 
deaths and the overall, age- and disease-specific case fatality rates (CFRs). Furthermore, most health information systems record only one diagnosis; this leads to a significant underestimation of common comorbidities, such as malnutrition, HIV and anaemia. The PHR therefore needed to record comorbidities; without any double-counting of patient numbers, the automated calculations help to understand the contribution of these comorbidities to morbidity and mortality. The programme also needed to include simple illness severity metrics so that differences in CFRs over time and differences between health facilities may be better understood. These included severe pneumonia, which has a standardised definition that is well understood by health workers, ${ }^{4}$ and very low birth weight, an internationally accepted classification which uses an objective metric of weight (1000-1499 g).

\section{Implementation and system requirements}

Some hospitals had a computer in their wards; others required purchasing of a computer for use of the programme. The programme is designed for Windows-based operating systems and is installed via self-contained executable file either downloaded or distributed via universal serial bus or compact disc.

One day of hands-on training was provided for ward clerks, nurses and doctors in the 16 hospitals to enable them to use the programme. A printed discharge form was used as part of the routine medical record (see online supplementary appendix 1) and completed by the doctor or nurse discharging the patient. The data recorded were name, date of birth, address, weight, discharge diagnoses and outcome. The data form enabled a ward clerk or health worker to enter patient data after the child's discharge from the facility. Other data such as completeness of vaccination was added in the latest versions of the programme. The data entry programme needed to be intuitive, with minimal number of screens to navigate, and data entry needed to take less than 1 min per patient.

The data were collected and summarised in individual hospitals, where outcome data were automatically calculated on a summary sheet for any given time period (example in online supplementary appendix 2). This enabled the data to be used at a local level to monitor activity and disease patterns, for auditing and to plan local interventions. Each year the summary data from each hospital were collated at the National Department of Health. The Child Health Advisory Committee (CHAC), a highlevel stakeholder monitoring committee within the National Department of Health reviewed the annual data and made recommendations. Based on the PHR results and monitoring by the CHAC, Annual Reports on Child Morbidity and Mortality were produced each year 2010-2014. The PHR programme required one part-time coordinator in the Department of Health, who is also a vaccine-preventable disease surveillance officer for the country.

\section{RESULTS}

\section{Scale achieved}

In 6 years the PHR was introduced into 16 provincial hospitals (only 12 in the first year had the programme), documenting the causes of 96998 admissions, and 7128 child deaths, and annual admission and CFRs for 21 diseases or conditions (tables 1 and 2). Five annual child morbidity and mortality reports were produced (2010-2014), each distributed within 6 months of the conclusion of the reported year. ${ }^{5}$ This ensured national data were available in a timely fashion, and local data were immediately available.

The overall hospitals admission and death data from each hospital for each year are detailed in table 1, and CFRs per hospital
Table 1 Total admissions and outcomes for each hospital 20092014

\begin{tabular}{llcrl}
\hline Hospital & $\begin{array}{l}\text { No. of years } \\
\text { reporting }\end{array}$ & $\begin{array}{l}\text { Total } \\
\text { admissions }\end{array}$ & $\begin{array}{c}\text { Total } \\
\text { deaths }\end{array}$ & $\begin{array}{l}\text { Overall case } \\
\text { fatality rate } \\
(\%)\end{array}$ \\
\hline Alotau & 2 & 2492 & 49 & 1.97 \\
Angau & 4 & 8672 & 1016 & 11.72 \\
Buka & 6 & 3167 & 261 & 8.24 \\
Daru & & & & \\
Goroka & 6 & 16876 & 919 & 5.45 \\
Kavieng & 3 & 1084 & 63 & 5.81 \\
Kimbe & 5 & 5242 & 514 & 9.81 \\
Kerema & & & & \\
Kundiawa & 2 & 4695 & 342 & 7.28 \\
Manus & 3 & 988 & 16 & 1.62 \\
Mendi & 2 & 4405 & 235 & 5.33 \\
Modilon & 6 & 8063 & 794 & 9.85 \\
Mt Hagen & 4 & 15839 & 1129 & 7.13 \\
Nonga & 4 & 3088 & 213 & 6.90 \\
Popendetta & 2 & 2810 & 216 & 7.69 \\
Port Moresby & 3 & 12976 & 911 & 7.02 \\
Vanimo & 3 & 2290 & 96 & 4.19 \\
Wabag & 5 & 3265 & 276 & 8.45 \\
Wewak & 1 & 1046 & 50 & 4.78 \\
Total & 61 & 96998 & 7128 & 7.35 \\
\hline
\end{tabular}

and per common disease are illustrated in figures 1 and 2, respectively. Not all hospitals were able to report each year. The numbers of hospitals that were able to report each year were 7 , $11,11,10,10$ and 12 in 2009 to 2014, respectively. This amounted to a total of 61 hospital-years of complete reporting. Reasons that hospitals were unable to report fully in any given year were often computer problems (such as a virus that shut down a computer), or staffing problems (ward clerk leaving and a gap between appointments).

The PHR programme was updated several times over the 6 years; faults were corrected, and new diagnoses were added based on consensus among the Paediatric Society and the Health Department. These included rheumatic heart disease/ acute rheumatic fever, cancer, child protection issues and disaggregation of tuberculosis $(\mathrm{Tb})$ to pulmonary and extrapulmonary $\mathrm{Tb}$, and more recently multidrug resistant $\mathrm{Tb}$ and injuries and trauma. In the latest version (PHR11 2015, data not shown) maternal and birth data will be included to better support the integration of maternal newborn and child health.

\section{Guiding policy and practice}

Over the 6 years of the PHR many findings were used to guide policy and action, the following are just some examples. The Health Department used the PHR results to prioritise interventions within the PNG Child Health Policy and Plan, ${ }^{6}$ a document that sets out a blueprint for child health from 2009 to 2020, and was revised in 2014-2015, drawing heavily on the PHR data. The high prevalence of severe malnutrition among admissions (12\%) and the high CFR for severe malnutrition (above 20\% in 2010 and 2012) prompted quality improvement (QI) research projects in two hospitals, training of staff throughout the country on management of severe malnutrition and the introduction of ready-to-use therapeutic feeds and Formula F75 and F100 by the Health Department, supported by Unicef. The QI projects were run by trainee paediatric registrars and thus 
Table 2 Admissions, deaths and case fatality rates for common diagnoses 2009-2014

\begin{tabular}{|c|c|c|c|c|c|c|c|c|}
\hline Diagnoses & $\begin{array}{l}\text { Deaths/ } \\
\text { admissions } 2009\end{array}$ & $\begin{array}{l}\text { Deaths/ } \\
\text { admissions } \\
2010\end{array}$ & $\begin{array}{l}\text { Deaths/ } \\
\text { admissions } \\
2011\end{array}$ & $\begin{array}{l}\text { Deaths/ } \\
\text { admissions } \\
2012\end{array}$ & $\begin{array}{l}\text { Deaths/ } \\
\text { admissions } \\
2013\end{array}$ & $\begin{array}{l}\text { Deaths/ } \\
\text { admissions } \\
2014\end{array}$ & $\begin{array}{l}\text { Total deaths/ } \\
\text { admissions }\end{array}$ & $\begin{array}{l}\text { Case } \\
\text { fatality } \\
\text { rate }\end{array}$ \\
\hline All paediatric admissions & 209/3456 (6.94) & $646 / 10897$ & $1545 / 20582$ & $1660 / 20546$ & $1555 / 20543$ & $1482 / 20974$ & 7128/96998 & 7.35 \\
\hline Pneumonia & $24 / 836$ & $140 / 2504$ & 299/6330 & $272 / 5458$ & $261 / 5200$ & $294 / 5658$ & $1290 / 25986$ & 4.96 \\
\hline Severe pneumonia & $16 / 321$ & $119 / 697$ & $272 / 2322$ & $238 / 2476$ & $221 / 1909$ & $224 / 1818$ & $1090 / 9543$ & 11.42 \\
\hline Neonatal conditions & $88 / 834$ & $150 / 1596$ & $480 / 4180$ & $473 / 4012$ & $406 / 3437$ & $452 / 4981$ & $2049 / 19040$ & 10.76 \\
\hline Diarrhoea & $12 / 284$ & $35 / 1277$ & $52 / 2122$ & $67 / 1975$ & $120 / 2622$ & $109 / 2739$ & $395 / 11019$ & 3.58 \\
\hline Malaria & $26 / 507$ & $50 / 1814$ & $60 / 1774$ & $69 / 1263$ & 70/1347 & $67 / 1033$ & $342 / 7738$ & 4.42 \\
\hline Severe malnutrition & $61 / 344$ & $157 / 739$ & $287 / 1544$ & $604 / 2590$ & $524 / 3379$ & $455 / 2861$ & $2088 / 11457$ & 18.22 \\
\hline Tuberculosis & $16 / 164$ & $58 / 514$ & $145 / 1375$ & $199 / 1510$ & $241 / 2190$ & $179 / 1470$ & $838 / 7223$ & 11.60 \\
\hline Meningitis & $42 / 271$ & $92 / 417$ & $230 / 1305$ & $279 / 1452$ & $219 / 1374$ & $149 / 933$ & $1011 / 5752$ & 17.58 \\
\hline HIV & $3 / 20$ & $13 / 54$ & $37 / 195$ & $57 / 470$ & $61 / 378$ & $77 / 527$ & 248/1644 & 15.09 \\
\hline Anaemia* & & & & & $155 / 1015$ & $253 / 1455$ & $408 / 2470$ & 16.52 \\
\hline $\begin{array}{l}\text { Rheumatic heart } \\
\text { disease* }\end{array}$ & & & & & $4 / 58$ & $3 / 48$ & $7 / 106$ & 6.60 \\
\hline $\begin{array}{l}\text { Congenital heart } \\
\text { disease* }^{*}\end{array}$ & & & & & $10 / 24$ & $21 / 59$ & $31 / 83$ & 37.35 \\
\hline Measles & $0 / 1$ & $0 / 0$ & $0 / 2$ & $1 / 2$ & $1 / 2$ & $60 / 2098$ & $62 / 2105$ & 2.95 \\
\hline Cancer $^{*}$ & & & & & $18 / 47$ & $21 / 77$ & $39 / 124$ & 31.45 \\
\hline Tetanus & $0 / 2$ & $1 / 6$ & $0 / 47$ & $0 / 8$ & $0 / 0$ & $2 / 14$ & $3 / 77$ & 3.90 \\
\hline Acute flaccid paralysis & $0 / 6$ & $0 / 7$ & $0 / 15$ & $0 / 9$ & $1 / 6$ & $1 / 10$ & $2 / 53$ & 3.77 \\
\hline Whooping cough & $0 / 15$ & $0 / 16$ & $0 / 3$ & $0 / 41$ & $0 / 0$ & $1 / 15$ & $1 / 90$ & 1.11 \\
\hline Child protection* & & & & & $0 / 7$ & $3 / 35$ & $3 / 42$ & 7.14 \\
\hline
\end{tabular}

contributed to research training. The consistently high CFRs for severe pneumonia, meningitis, tuberculosis, HIV birth asphyxia and very low birth weight (figures 1 and 2) indicated that solely vertical interventions would have limited effect. As a more comprehensive response to the high CFR data the Paediatric Society of PNG introduced the WHO programme Hospital Care for Children in 2011. This teaches a QI approach to the care of sick children and newborns. Training has been done for over 200 nurses, health extension officers and doctors working in rural provinces, particularly those with high mortality reported through the PHR. Data on the causes of neonatal illness and death (figure 3) were hitherto unavailable, but through the PHR there are accurate disease burden and outcome data on neonatal sepsis, birth asphyxia and very low birth weight.

Consistently high CFRs for common conditions were reported from some hospitals, and consistently low CFRs from

\section{Hospital paediatric mortality rates 2009-2014}

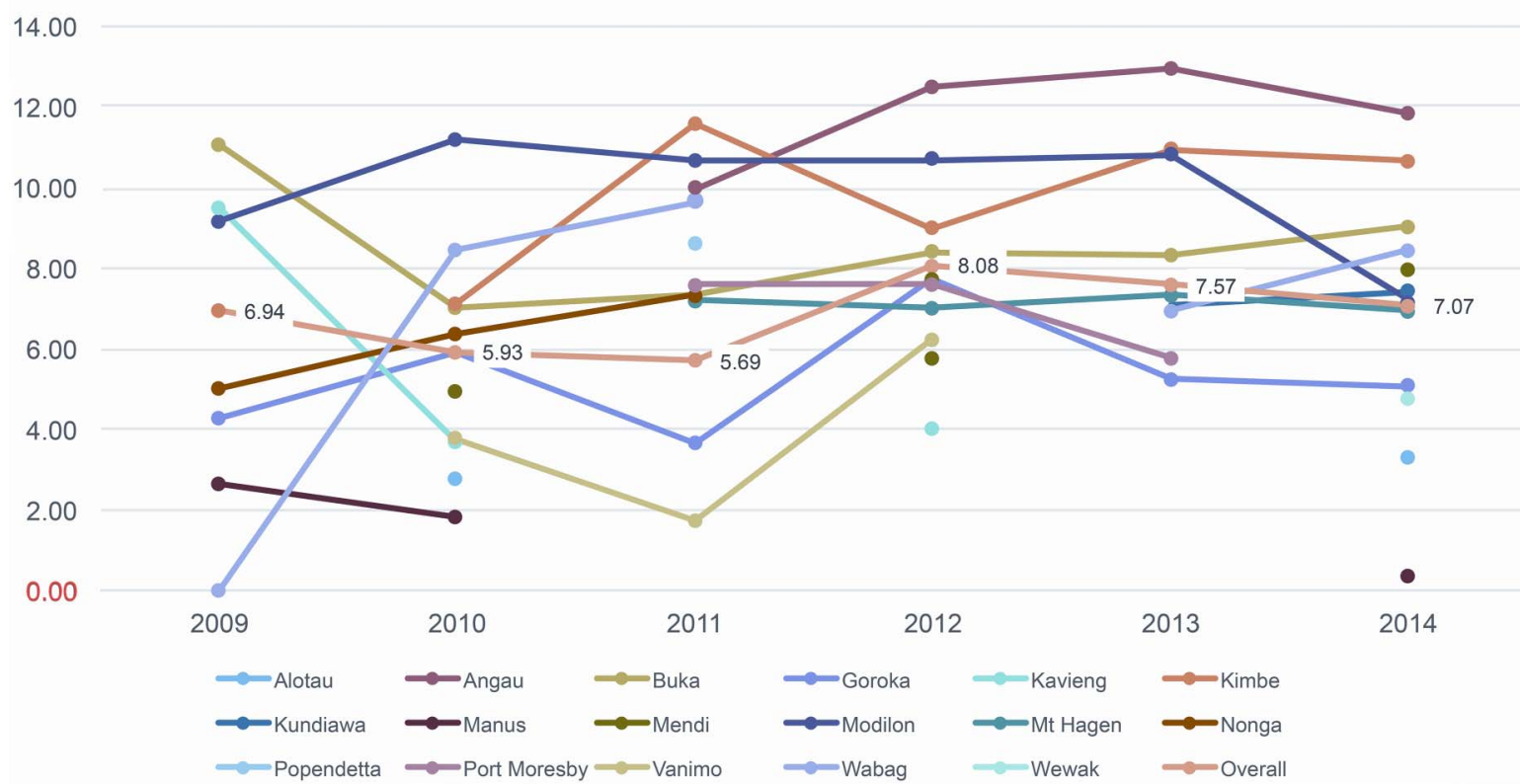

Figure 1 Paediatric case fatality rates per hospital 2009-2014. 
30.00

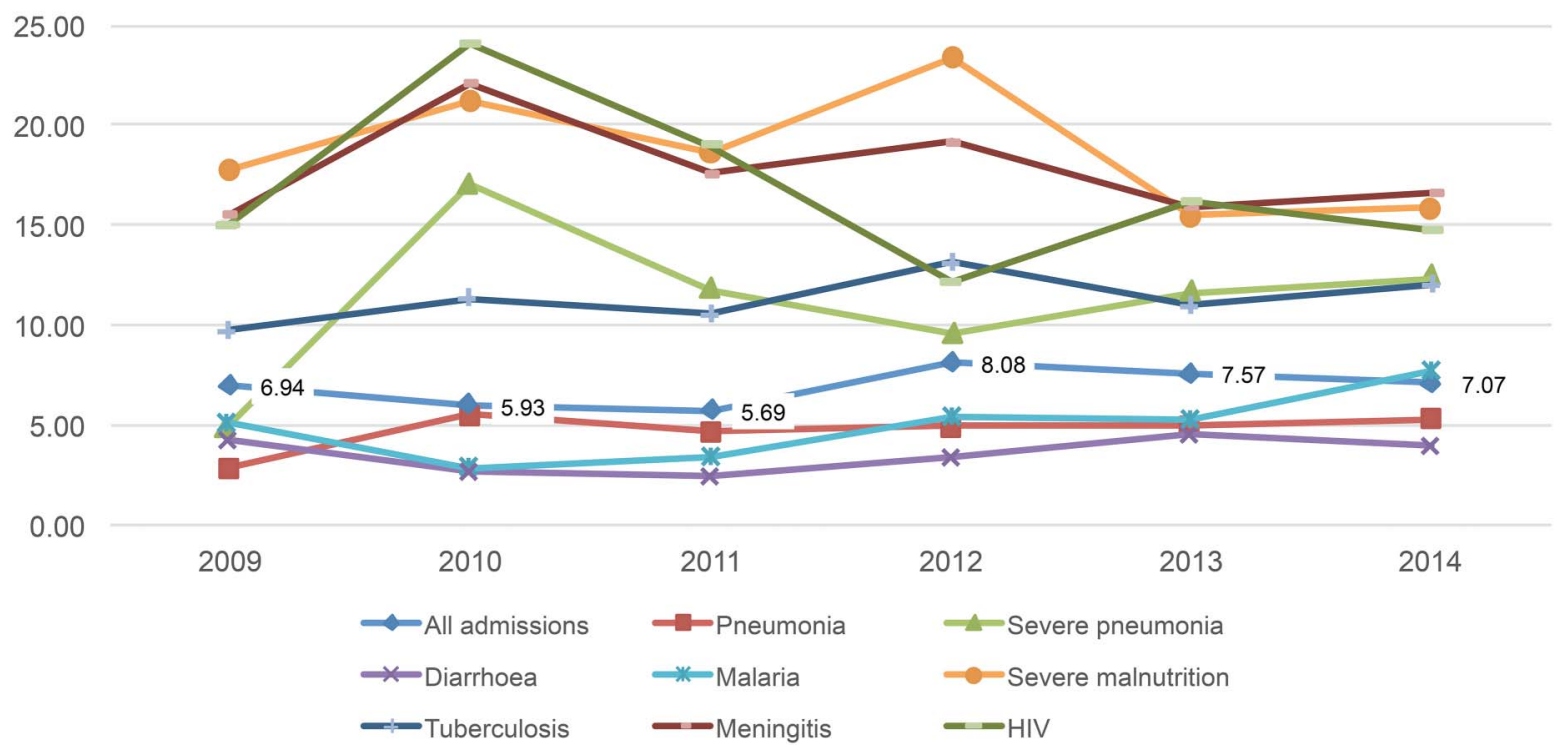

Figure 2 Common paediatric diagnoses and case fatality rates 2009-2014.

others. Examining these differences revealed difference in management, staffing levels and staff support. These data have aided in health worker deployment, training and other interventions to assist hospitals and provinces in greatest need. Each participating hospital uses their PHR data to audit, monitor performance and initiate local reforms as they interpret the data in their own context. They generate summaries over any time period chosen, for monthly audits or annual reporting to the Health Department. High mortality rates from very low birth weight have led to local facility upgrades in special care nurseries. In one hospital the high rate of anaemia as a comorbidity has prompted research to investigate the cause. A major measles outbreak of 2014 was captured in the PHR, and the PHR improved surveillance for other vaccine-preventable diseases including pertussis, tetanus and acute flaccid paralysis. Nurses, doctors and administrators appreciate the better understanding of their own hospital's data, and this has driven local initiative and changes. Data were presented in local audit meetings.

No more than US\$20000 was needed each year to fund the coordination of the programme, gather the summary data from

\section{Mortality rates for neonatal conditions 2009-2014}

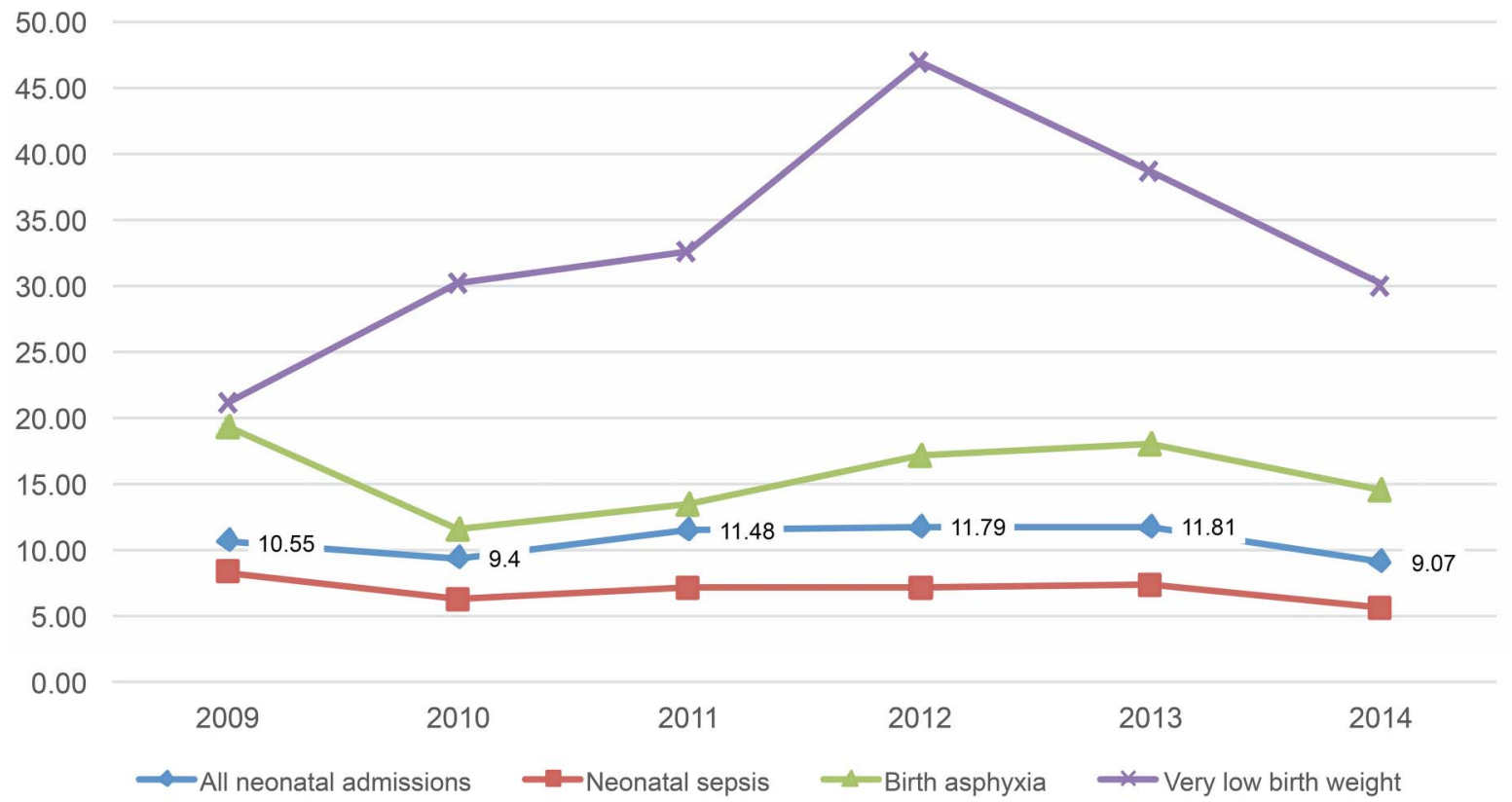

Figure 3 Neonatal diagnoses and case fatality rates 2009-2014. 
hospitals and compile it into an annual report. The Health Department funded the salary of the surveillance officer who was already employed in the expanded programme of immunisation unit; WHO provided funding for that officer's travel to provinces for 3 years, and the Health Department funded travel for the subsequent years; a philanthropic trust funded six computers. Other costs-for example, hospital staff who used the programme-were routine healthcare costs.

\section{DISCUSSION}

The WHO and the United Nations recommend that member states use the ICD. ICD classification had its origins in 1891 at The International Statistics Congress in Vienna. Jacques Bertillon, Chief of Statistics for the City of Paris, presented three candidate lists of 44, 99 and 161 conditions, plus subdivisions. This became the first edition: International List of Causes of Death. ${ }^{7}$ By 1948 the sixth edition had been produced and WHO took responsibility for the ICD, publishing the causes of morbidity for the first time. In 1967 at the World Health Assembly, WHO stipulated that all member states should use ICD in its most current revision for mortality and morbidity statistics, and in 1990 ICD-10 was endorsed by the Forty-third World Health Assembly. It now has 69823 diagnostic codes and 71924 procedure codes, ${ }^{8}$ requires prolonged training to develop competence in coding and the infrastructure required is expensive. In 2005, 75 countries had no data on the cause of deaths from 1990 onwards, and 39 had no data at all. These 75 included $90 \%$ of countries in Africa, more than $60 \%$ of countries in South Asia and 37\% of countries in Western Pacific. PNG was one of these. ${ }^{1}$

Unfortunately in most low- and middle-income countries health information systems are overly complex, contain multiple sources of error, are increasingly vertical and are usually poor representations of child and neonatal illnesses. Data are difficult to access by health policy makers and clinicians, rarely fed back to or usable by the health workers who collect the data and rarely used to guide policy and practice, especially at the local level.

The PHR programme was designed to address these deficiencies in routine data. It was developed and successfully introduced in PNG, a resource-limited low/middle-income country with a population of over 7 million, $85 \%$ of whom live in rural provinces. The geography and infrastructure in remote PNG makes gathering accurate and representative data most difficult. The participating hospitals are remote and all require air travel from the capital, Port Moresby, to visit. They are understaffed, with nurse:patient ratios of up to $20: 1$, and typically have one paediatrician for a population of 200000 . Internet services in provinces in PNG have improved in the last 6 years, but are unreliable and often expensive.

To develop the PHR we used standardised WHO diagnoses that can be made using clinical assessment and sometimes minimal laboratory investigations. These diagnostic tools are accessible to provincial and district hospitals in low-income countries. The diagnoses include all common causes of childhood illness and death in low/middle-income countries, vaccine-preventable diseases and some neglected and emerging diseases. In low/middle-income countries it is common for children to present with one symptom, but with more than one condition. For example, a child may have pneumonia and anaemia, or tuberculosis and malnutrition, or chronic diarrhoea and HIV. Children most likely to die have more than one diagnosis, and each diagnosis must be identified and managed if CFRs are to fall, and all diagnoses need to be reported to enable a more complete understanding of child health epidemiology. For example, in PNG before the PHR, the health information system (HIS) suggested that only $2 \%$ of all admissions had severe malnutrition, but with coding of comorbidities it is evident that the true prevalence is over $10 \%$.

Increasingly, disability and social problems are identified as causes of child morbidity, and the programme has updated to include the recording of important social problems, for example, child protection issues and informal adoption. Adding data on other social determinants of health may be important in the future for better understanding equity issues, but with each addition consideration has to be given to the effect of increasing complexity on ease of use, data completeness and accuracy.

Prior to the PHR there was no HIS that enabled the understanding of age- and disease-specific causes of admission or CFRs, and the causes of neonatal illness and deaths were not recorded. The PHR does not replace the need for good population-based data, or vital registration, ${ }^{9}$ or studies which understand the proximal and distal causes of childhood illness and death. However, these have proved extremely difficult in many poor countries. Currently in many low/middle-income countries population-based data are only available via demographic and health surveys or census, done every 5-10 years. These surveys suffer from the problems of most routine HISthe lack of timely results and results not being fed back to health workers and communities which collect the data. In the absence of up-to-date data, many estimates of global disease burdens over the last 15 years have used modelled data. ${ }^{10}{ }^{11}$ While these provide important global estimates they can be a further disincentive to developing real data sources that are trusted by health workers and policy makers in low/middle-income countries.

Other countries have reported similar efforts at local and national data collection. In South Africa there is a national data base for recording of maternal, newborn and child deaths. ${ }^{12}$ The Child Healthcare Problem Identification Programme used computer-based tools to review in-hospital deaths. ${ }^{13}$ Using information derived from these mortality reviews, interventions at local and national levels lead to measurable improvements in quality of care, including increasing the availability and uptake of maternal-to-child HIV transmission prevention. In 2015 staff at the Kenya Medical Research Institute reported on the first year of a clinical data management system that had been implemented in 14 hospitals. They reported improvements in clinical documentation of admissions, and tracking of clinical performance indicators, such as the assessment of clinical signs of dehydration. ${ }^{14}$ There are other examples of prospective and retrospective neonatal, perinatal and child mortality auditing from single hospitals, ${ }^{15-18}$ but few at wider scale.

Implementation of the PHR programme in PNG has faced some challenges, incomplete reporting with several hospitals not being able to report in some years because of problems with the computer system being a major one. The PHR programme is not prone to viruses, but if computers are used for other purposes viruses can effectively shut down the programme. Quality control is also difficult, but we cross-checked the number of admissions and deaths in several hospitals and these matched closely the number of children in admission record books.

We have shown that real data can be reported at a significant scale from remote hospitals in a low/middle-income country and that the programme can be sustained over time and expanded in ways that are appropriate to emerging needs, and used for local and national initiatives to improve child health. The PHR is now being introduced in Laos People's Democratic Republic and the Solomon Islands, and is available free at http://tinyurl. com/pdpxktp (or a copy of the PHR programme can be obtained from the corresponding author on request). 


\section{Author affiliations}

${ }^{1}$ Centre for International Child Health, University of Melbourne, MCRI, Royal Children's Hospital, Parkville, Victoria, Australia

${ }^{2} S c h o o l$ of Medicine and Health Sciences, University of Papua New Guinea, Port Moresby, Papua New Guinea

${ }^{3}$ Disease Surveillance Branch, PNG National Department of Health, Waigani, NCD, Papua New Guinea

${ }^{4}$ Electronic Medical Record, Royal Children's Hospital, Parkville, Victoria, Australia ${ }^{5}$ Department of Paediatrics, Goroka General Hospital, Goroka, Eastern Highlands, Papua New Guinea

${ }^{6}$ Department of Paediatrics, Modillon Hospital, Madang, Madang Province, Papua New Guinea

${ }^{7}$ Department of Paediatrics, Buka Hospital, Buka, Autonomous Region of Bouganville, Papua New Guinea

${ }^{8}$ Department of Paediatrics, Kimbe Hospital, Kimbe, West New Britain Province, Papua New Guinea

${ }^{9}$ Department of Paediatrics, Angau Hospital, Lae, Morobe Province, Papua New Guinea

${ }^{10}$ Department of Paediatrics, Rabaul Hospital, Rabaul, East New Britain, Papua New Guinea

${ }^{11}$ PNG National Department of Health, Family Health Services, Port Moresby, NCD, Papua New Guinea

${ }^{12}$ Department of Paediatrics, Port Moresby General Hospital, Port Moresby, NCD,

Papua New Guinea

Acknowledgements We thank the RE Ross Trust (Victoria), for assistance with funding, and thank the numerous nursing staff and ward clerks in the participating hospitals who enthusiastically recorded and used the routine data.

Contributors The Paediatric Society of Papua New Guinea identified the need for more accurate data on hospital admissions and outcomes. TD and AH designed the Paediatric Hospital Reporting tool. All authors gathered data from their institutions. EY and TD collated the data annually. TD wrote the first draft of the paper. All authors reviewed the draft and contributed to the final version.

Competing interests None declared.

Ethics approval PNG National Department of Health.

Provenance and peer review Not commissioned; externally peer reviewed.

Open Access This is an Open Access article distributed in accordance with the Creative Commons Attribution Non Commercial (CC BY-NC 4.0) license, which permits others to distribute, remix, adapt, build upon this work non-commercially, and license their derivative works on different terms, provided the original work is properly cited and the use is non-commercial. See: http://creativecommons.org/ licenses/by-nc/4.0/

\section{REFERENCES}

1 Mathers $C D$, Fat DM, Inoue $M$, et al. Counting the dead and what they died from: an assessment of the global status of cause of death data. Bull World Health Organ 2005:83:171-7.
2 Bah S. Strategies for managing the change from ICD-9 to ICD-10 in developing countries: the case of South Africa. I Health Informatics Dev Countries 2009;3:44-9.

3 World Health Organization. IMCI Chart Booklet. 2013:1-80. http://apps.who.int/iris/ bitstream/10665/104772/16/9789241506823_Chartbook_eng.pdf (accessed Mar 2014).

4 World Health Organization. Hospital care for children: guidelines for the management of common illnesses with limited resources. 2nd edn. Geneva: WHO, 2013. ISBN: 789241548373. http://www.who.int/maternal_child_adolescent/ documents/child_hospital_care/en/

5 Child Health Advisory Committee. Child Morbidity and Mortality: Annual Reports 2010-14. PNG National Department of Health, 2014:1-5. http:/l pngpaediatricsociety.org/reports/annual-child-morbidity-and-mortality-reports-2010

6 PNG Department of Health. The Papua New Guinea Child Health Policy and Plan 2009-2020. 1st edn. Port Moresby: PNG Department of Health, 2009. http:/l pngpaediatricsociety.org/wp-content/uploads/2013/06/PNG-Child-Health-Policy-andPlan-2009-2020.pdf

7 Moriyama IM, Loy RM, Robb-Smith AHT. History of the statistical classification of diseases and causes of death. Hyattsville, MD: National Center for Health Statistics, Centers for Disease Control and Prevention, 2011.

8 Centers for Disease Control. International Classification of Diseases, (ICD-10-CM/ PCS) Transition. National Center for Health Statistics, 2015. http://www.cdc.gov/ nchs/icd/icd10cm_pcs_background.htm (accessed 8 Sep 2015).

9 Rao C, Bradshaw D, Mathers CD. Improving death registration and statistics in developing countries: lessons from sub-Saharan Africa. S Afr I Demog 2004;9:81-99.

10 Black RE, Morris SS, Bryce J. Where and why are 10 million children dying every year? Lancet 2003;361:2226-34.

11 Bryce J, Boschi-Pinto C, Shibuya K, et al. WHO estimates of the causes of death in children. Lancet Infect Dis 2005;365:1152.

12 Bradshaw D, Chopra M, Kerber K, et al., South Africa Every Death Counts Writing Group. Every death counts: use of mortality audit data for decision making to save the lives of mothers, babies, and children in South Africa. Lancet 2008;371:1294-304.

13 Krug A, Pattinson RC. Saving Children 2004: a survey of child healthcare in South Africa. University of Pretoria and MRCH Unit for Maternal and Infant Health Care Strategies, 2004. ISBN: No 0-620-33837-7.

14 Tuti T, Bitok M, Paton C, et al. Innovating to enhance clinical data management using non-commercial and open source solutions across a multi-center network supporting inpatient pediatric care and research in Kenya. J Amer Med Informatics Assoc 2015;0:1-11.

15 Nzioki C, Irimu G, Musoke R, et al. Audit of care for children aged 6 to 59 months admitted with severe malnutrition at Kenyatta National Hospital, Kenya. Int Health 2009;1:91-6.

16 Pattinson RC, Makin JD, Shaw A, et al. The value of incorporating avoidable factors into perinatal audits. S Afr Med J 1995;85:145-7.

17 Duke T, Michael A, Mgone J, et al. Etiology of child mortality in Goroka, Papua New Guinea: a prospective two-year study. Bull World Health Organ 2002;80:16-25.

18 Bucens IK, Reid A, Barreto AC, et al. Three years of neonatal morbidity and mortality at the national hospital in Dili, East Timor. J Paeds Child Health 2013:49:452-7. 